\title{
ACTIVE DISCHARGE OF DC LINK CAPACITOR IN SRM DRIVE FOR ELECTRIC VEHICLE APPLICATION
}

\author{
Deepak G \\ M.Tech, Power Electronics \\ Dept. of Electrical and Electronics Engineering \\ BMS College of Engineering, Bengaluru, India
}

\begin{abstract}
Switched Reluctance motor is gaining much importance in automotive industries because of simple construction, no permanent magnets on the rotor, high torque to inertia ratio and low cost. A DC link capacitor is connected between the positive and negative bus terminals of the high voltage DC source in an Inverter circuit. An active discharge circuit is connected across the DC link capacitor which consists of a switch in series with the discharge resistors. The discharge switch has a control terminal which can define the discharge rate. In an electric vehicle application, which uses the supply voltage greater than $400 \mathrm{~V}$, it is necessary to discharge the capacitor during the vehicle shutdown or when the vehicle encounters a severe fault. Simulation of active discharge process in an SRM drive with MATLAB Simulink results is presented in this paper.
\end{abstract}

Keyword-Active Discharge, Electric Vehicles, Discharge resistors, SRM drive.

\section{INTRODUCTION}

The use of switched reluctance motor [SRM] in recent days has increased drastically. It is also very likely to be a very good contender for its application in electric vehicles. The SRM needs a special kind of drive for its operation. Even though various control strategies have been developed to assure that the motor is operating at its high efficiency, a safe way to shut it down immediately during the emergency condition should also be known when being used in an electric vehicle.

A DC link capacitor is connected between the positive and negative bus terminals of the high voltage DC source in an Inverter circuit. This capacitor voltage could be above $400 \mathrm{~V}$ and can go up to $900 \mathrm{~V}$ in an electric car. During the vehicle key-off event or when the vehicle encounters a severe fault in running condition, the charge in the capacitor must be discharged to a safer limit so that it does not cause any additional hazard in the fault condition. One such example

\author{
Dr. Chandasree Das \\ Associate Professor \\ Dept. of Electrical and Electronics Engineering \\ BMS College of Engineering, Bengaluru, India
}

where the vehicle is running and encounters a severe fault and the system must shutdown is the event of vehicle crash.

The two simplest conventional techniques which can be used for capacitor discharge are active discharge (AD) and passive discharge techniques. The passive discharge technique involves connecting a very high resistance in parallel with the DC-link capacitor which is necessary to avoid excessive power loss during normal operation. Consequently, this discharge technique might take one to two minutes to dissipate the high voltage charge to a safer value. In certain situations (such as the event of vehicle crash), it might be required to discharge the capacitor in a much shorter time (e.g., 5 seconds). Therefore, an active discharge technique is suitably used in such a situation. An active discharge circuit consists of a resistor controlled by a series switch. The discharge switch has a control terminal which can define the discharge rate.

In this paper, the simulation of SRM drive with the demonstration of the active discharge technique is proposed. The circuit is simulated with MATLAB-Simulink and the results are presented.

\section{SRM DRIVE IN AN ELECTRIC VEHICLE}

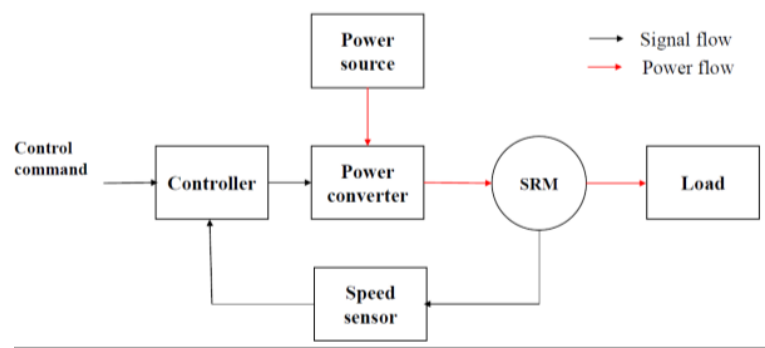

Figure 1:Block diagram of SRM used in Electric vehicle

Figure 1 shows the block diagram of the SRM drive used in Electric vehicles. An Electric motor is used as a primary propulsion system in an electric vehicle. The electric vehicle is usually powered by a DC power source and through a power converter, it is fed to the motor. The control command is received by sensing the output from the acceleration sensor. 
The speed and position of the motor can be obtained by a hall effect sensor.

When the vehicle is subjected to a severe fault condition, the system should be able to keep the driver safe in the vehicle. This reaction could be either stopping the motor or providing the limited features functional so that the driver is able to take the vehicle to a safe place.

\section{ISSUES WITH THE EXISTING METHODS FOR DISCHARGING THE DC-LINK CAPACITOR}

Figure 2 represents the SRM Drive where the motor is fed by three-phase asymmetrical converter. The Active discharge circuit consists of the resistor and MOSFET (Brake chopper) which is in parallel with the DC-link capacitor.

In a vehicle key-off event, the battery will be disconnected from the power converter by a relay to suspend the source and also for battery protection.

In a vehicle key-off event or in situations where the vehicle is running and encounters a crash, the motor cannot be stopped instantaneously. The rotor shaft of the electric machine will be decoupled from the gear mechanism but it will be still in running condition due to mechanical inertia. This might affect the capacitor discharge depending on the speed at which the machine is running.

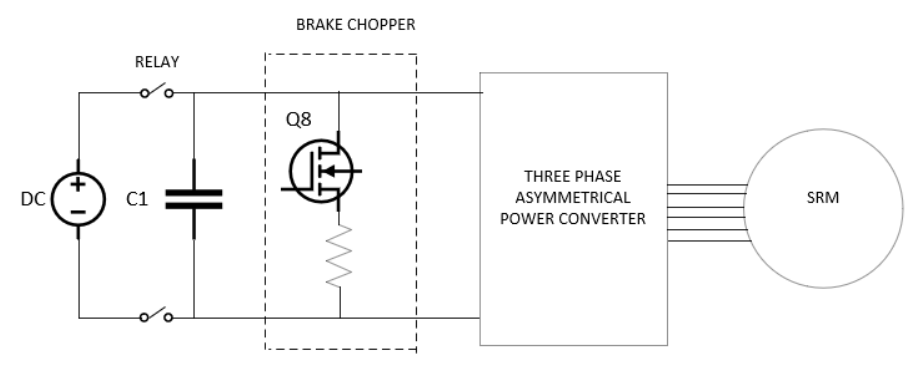

Figure 2: Switch reluctance motor drive

To avoid the effect of the motor EMF on the capacitor discharge, a simple method is to short all the IGBT switches in the converter. This approach prevents the current flow from the electric machine to the capacitor by shorting the terminals of the stator. The main problem of this method is that the short circuit current which flows inside the machine may cause unrecoverable damage to the electric machine (Nutan and Choudhory et al.,2016). Adding a brake chopper unit in parallel with the DC-link capacitor will reduce the DC bus voltage which is illustrated in this scope.

The DC-link capacitor can be discharged through the resistor which is present in the chopper unit when the MOSFET is turned on. Whenever the DC bus voltage drops below the
EMF of the machine, the current will flow through the inverter diodes and charge the DC-link capacitor. Therefore, the resistor has to absorb not only the energy stored in the capacitor but also the mechanical energy left in the machine. As a result, the resistor used in the chopper unit can often be large. Nevertheless, the capacitor cannot be completely discharged because the speed of the motor decreases much slower than the DC bus voltage.

\section{ACTIVE DISCHARGE TECHNIQUE}

Figure 3 represents the flow chart that shows how the vehicle system should behave in case of a fault scenario. As a primary step, the vehicle Ignition switch (Vehicle key) is monitored and when there is a vehicle key-off event, the passive discharge shall be activated. Suppose the vehicle is in running state and encounters a severe fault which will not only damage the motor, also other subsystems causing injuries to the driver as well. So, the system should be stopped immediately after encountering the fault. In such cases, the capacitor voltage is read and when the voltage is greater than $60 \mathrm{~V}$, the active discharge shall be activated and the motor shall be stopped. This whole process will happen in a few seconds. If the voltage is less than $60 \mathrm{~V}$, the active discharge shall not be active as this voltage is below safety level and this will be taken care of by the passive discharge technique.

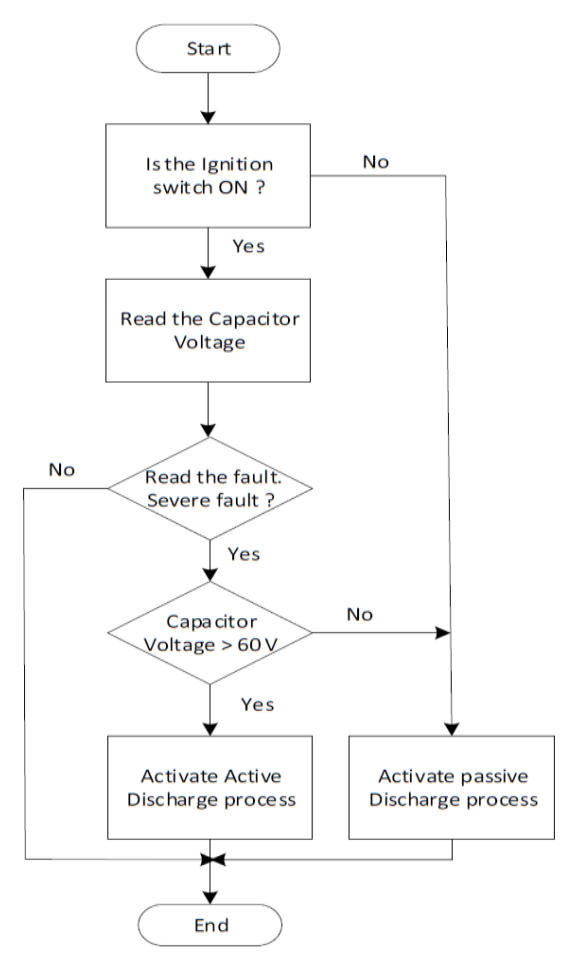

Figure 3: Flowchart of Active Discharge Technique 
International Journal of Engineering Applied Sciences and Technology, 2020

Vol. 5, Issue 3, ISSN No. 2455-2143, Pages 568-571

Published Online July 2020 in IJEAST (http://www.ijeast.com)

\section{SIMULATION IN MATLAB SIMULINK}

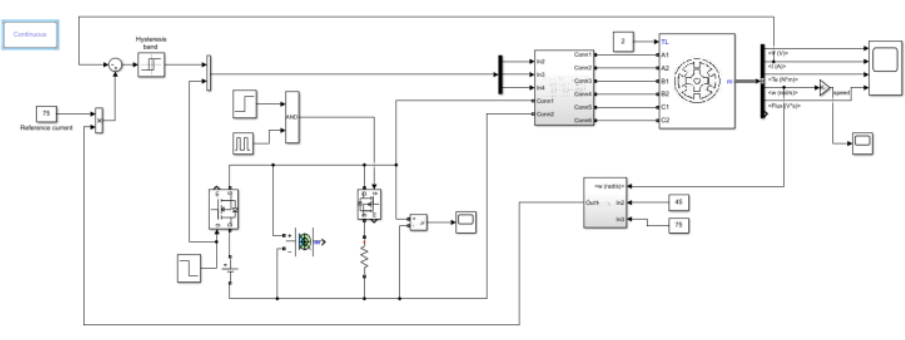

Figure 4: SRM drive with Active discharge circuit

Figure 4 shows the SRM drive with an Active discharge circuit simulated with MATLAB Simulink. The SRM is fed by a three-phase asymmetrical power converter which consists of two IGBT's and two freewheeling diodes.

Active discharge is initiated at time $t=0.5 \mathrm{~s}$ assuming that the vehicle encounters a severe fault, expecting the vehicle shutdown. The phase currents are controlled by the hysteresis controller and the motor position is sensed by a position sensor. The turn-on and turn-off angles are given to be $45 \mathrm{deg}$ and $75 \mathrm{deg}$ respectively.

The motor parameters used for the simulation are shown in table 1 .

Table -1 Motor Specifications

\begin{tabular}{|c|c|}
\hline PARAMETER & VALUE \\
\hline Rated Voltage & $500 \mathrm{~V}$ \\
\hline Rated Current & $100 \mathrm{~A}$ \\
\hline Rated Power & $500 \mathrm{KW}$ \\
\hline Number of Stator poles & 6 \\
\hline Number of Rotor poles & 4 \\
\hline
\end{tabular}

A positive voltage is applied to the stator windings when the IGBTs are conducting. During the freewheeling period, a negative voltage is applied to the windings and the stored energy in the windings is returned to the source through the freewheeling diodes. The voltage, current, torque and the flux waveforms are plotted for the pre-fault and post-fault conditions as shown in the figure 5 .
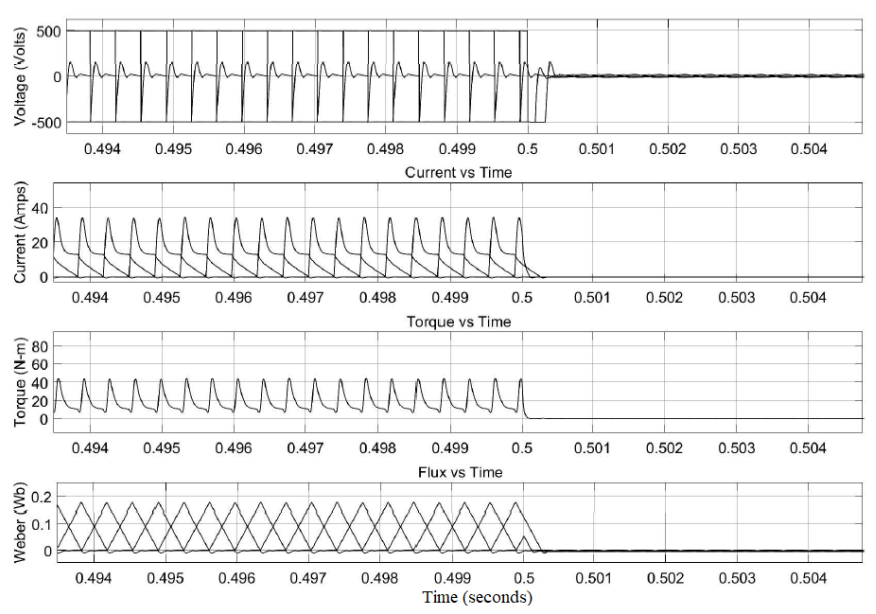

Figure 5: Voltage, Current, Torque \& flux vs time

The speed slowly drops down to zero whenever a fault condition in the vehicle is encountered as shown in the waveform of figure 6 . The motor shaft will be disconnected from the gear mechanism of the vehicle but still the motor will be running due to the mechanical inertia.

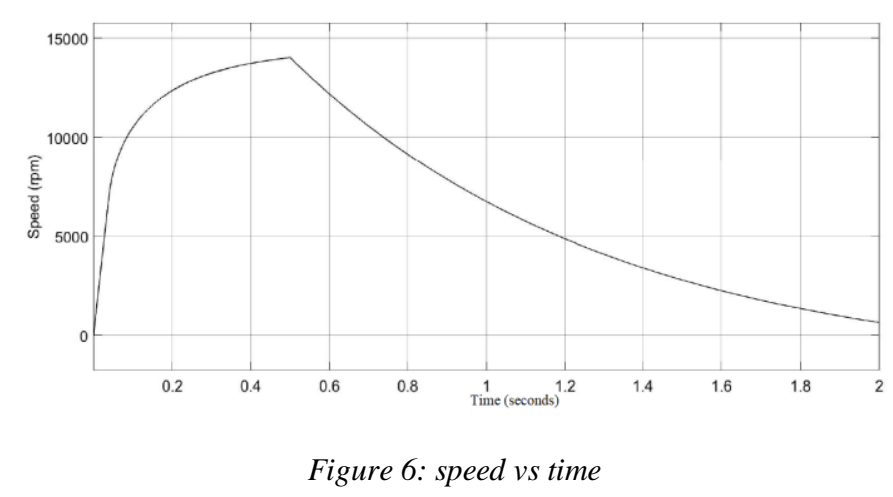

The DC bus voltage is plotted for different duty cycles of the MOSFET in the chopper circuit. By varying the duty cycle, the rate of discharge of the DC-link capacitor can be varied accordingly. Figure 7 and Figure 8 shows the DC bus discharge curve with duty cycle 0.05 and 0.9 respectively.

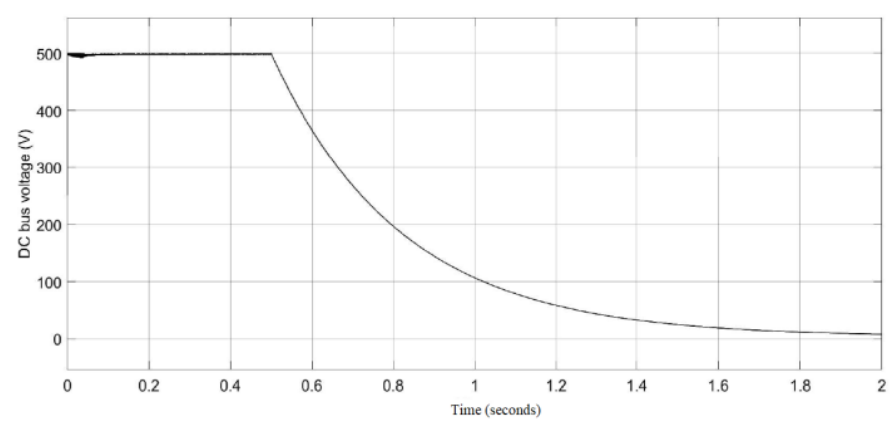

Figure 7:Bus voltage vs time (duty $=0.05$ ) 


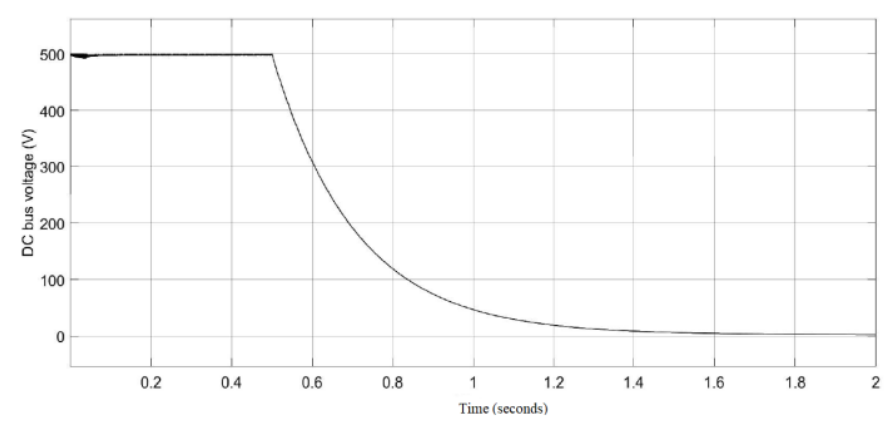

Figure 8:Bus voltage vs time (duty $=0.9)$

\section{CONCLUSION}

The Active discharge technique for the Switched reluctance motor is simulated using the MATLAB Simulink. In fault conditions, the active discharge will be activated and motor shaft will be disconnected from the drive mechanism. The motor will be running freely due to inertia. Whenever the DC bus voltage drops below the EMF of the machine, the current will flow through the inverter diodes to charge the DC-link capacitor and this is the only drawback of this technique. To avoid this situation, the DC bus voltage can be maintained at some voltage level greater than EMF of the machine during the discharge process and as the motor speed gradually falls to zero; the capacitor can be completely discharged.

\section{REFERENCES}

1. Nutan saha., D.S. Choudhory.(2016). Analysis of different types of faults exhibited in switched reluctance motor drives. International Conference on Advanced Communication Control and Computing Technologies (ICACCCT).

2. Aarim C Sijini., F Fantin., L.Prakash Ranjit.(2016). Swtiched Reluctance Motor for Hybrid Electric Vehicle, Middle-East Journal of Scientific Research, IDOSI Publications.

3. Taro Genda., Hideo Dohmeki.(2009). Characteristics of 4/2 Switched Reluctance Motor for high speed drive for excitation angle, International conference on Electrical machines and systems.

4. S. Kachapornkul., P Jitkreeyarn., P. Somsiri., Tungpimolrut. (2007). A Design of 15kW Switched Reluctance Motor for Electric Vehicle Applications, International conference on Electrical machines and systems.

5. Krishnan Ramu.(2001). Switched Reluctance Motor drives, Modeling, Simulation, Analysis, Design, and Applications.
6. Mehrdad Ehsani., Yimin Gao., Sebasttien E. Gay., Ali Emadi.(2005). Modern Elctric, Hybrid Electric, and Fuel Cell Vehicles.

7. R.M. Pindoriya., B S Rajpurohit., R.Kumar., K N Srivastava. (2018). Comparative Analysis of Permanent Magnet Motors and Switched Reluctance Motors Capabilities for Electric and Hybrid Electric Vehicles, IEEMA Engineer Infinite Conference (eTechNxt)

8. Pavol Rafajdus., Adrian Peniak., Milan Diko., Makarovic Dubravka., Valeria Hrabovcova. (2016). Using of Suitable Reluctance Motors for Electric Vehicles and Comparison of their Performances, IEEE $15^{\text {th }}$ International Conference on Environment and Electrical Engineering(EEEIC)

9. L. Venkatesha., V. Ramanarayanan.(1998). Torque ripple minimization in switched reluctance motor with optimal control of phase currents, International conference on power electronics drives and energy systems for industrial growth, 1998. Proceedings.

10. Kirti R Chichate., Sachin R Gore., Ajar Zadey.(2020). Modeling and simulation of Switched Reluctance Motor for Speed Control Applications, $20202^{\text {nd }}$ International conference on Innovative Mechanisms for Industry Applications

11. S. Roop Kumar., D Susitra. (2016). A SRM Drive based Hybrid Electric Vehicle with Reduced Switch converter,2016 Online International Conference on Green Engineering and Technologies(IC-GET)

12. Maged N F Nashed., Kazuhiro Ohyama., Kenichi Aso., Hiroaki Fujii., Hitoshi Uehara.(2006). Automatic Turn-off Angle Control for High Speed SRM Drive, 2006 IEEE International Symposium on Industrial Electronics. 